\title{
Scaling of Performance in Liquid Propellant Rocket Engine Combustion Devices
}

\author{
James R. Hulka* \\ Jacobs Engineering ESTS Group, Huntsville, AL, 35812
}

\begin{abstract}
This paper discusses scaling of combustion and combustion performance in liquid propellant rocket engine combustion devices. In development of new combustors, comparisons are often made between predicted performance in a new combustor and measured performance in another combustor with different geometric and thermodynamic characteristics. Without careful interpretation of some key features, the comparison can be misinterpreted and erroneous information used in the design of the new device. This paper provides a review of this performance comparison, including a brief review of the initial liquid rocket scaling research conducted during the 1950s and 1960s, a review of the typical performance losses encountered and how they scale, a description of the typical scaling procedures used in development programs today, and finally a review of several historical development programs to see what insight they can bring to the questions at hand.
\end{abstract}

\section{Nomenclature}

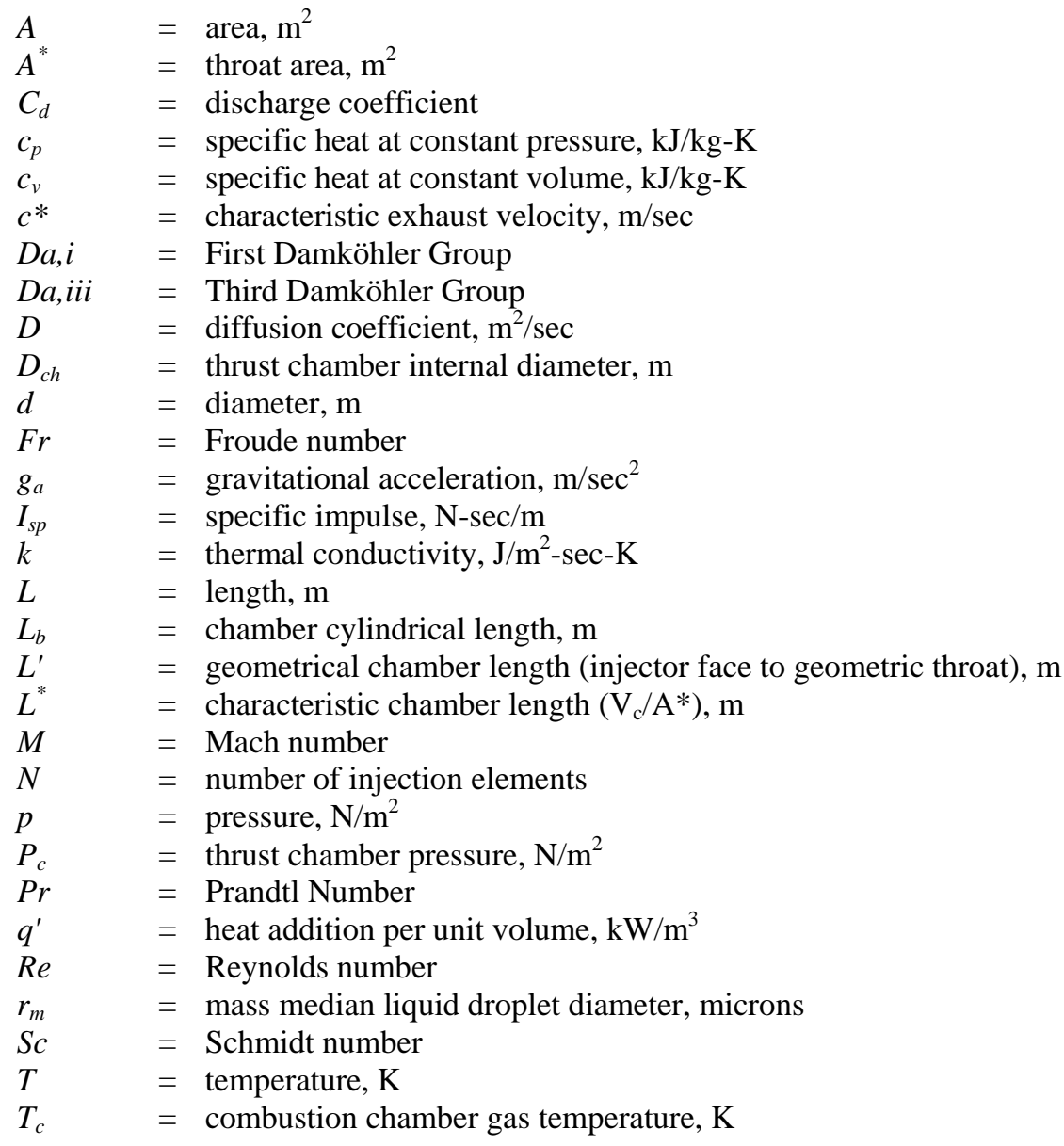

\footnotetext{
* Engineering Specialist, ER32, Mail Stop ER32, NASA MSFC, Senior Member AIAA.
} 


$\begin{array}{ll}V_{c} & =\text { chamber volume, } \mathrm{m}^{3} \\ v & =\text { velocity, } \mathrm{m} / \mathrm{sec} \\ W e & =\text { Weber number } \\ X_{i a} & =\text { multielement interaction index } \\ \gamma & =\text { specific heat ratio } \\ \eta_{c^{*}} & =\text { characteristic velocity efficiency } \\ \mu & =\text { absolute viscosity, } \mathrm{kg} / \mathrm{m} \text {-sec } \\ v & =\text { kinematic viscosity, } \mathrm{m}^{2} / \mathrm{sec} \\ \rho & =\text { density, } \mathrm{kg} / \mathrm{m}^{3} \\ \tau & =\text { characteristic delay time, sec } \\ \tau_{i} & =\text { characteristic conversion time of chemical species } i, \mathrm{sec} \\ \tau_{r} & =\text { relaxation time, sec }\end{array}$

\section{Introduction}

S CALING of combustion devices for Liquid Propellant Rocket Engines (LPREs) has never been fully developed, $\checkmark$ analytically or experimentally, even though the first formal studies for rocket engines were conducted more than 50 years ago, and Damköhler's seminal papers were published nearly 70 years ago. Nevertheless, scaling still remains a powerful potential tool for the development of new combustion devices for LPREs, especially in the current era where significantly reduced financing is available for rocket engine development.

Scaling has been defined as "the ability to design new combustion devices with predictable performance on the basis of test experience with old devices."1 Historically, this meant changing - usually increasing - the thrust level of an existing combustor to meet current needs. Usually, thrust was increased by increasing combustor size and mass flow rate, rather than pressure; often, nearly identical injection elements were packaged in a larger chamber. Today, some type of scaling is used in every development program, essentially when information from a previous program is used to create a new design. A well-defined and defensible scaling methodology thus has obvious advantages for development programs of LPRE combustion devices. At the highest level, a scaling methodology provides guidance, verification, and potential cost savings to the combustor design and development. Guidance may be provided to achieve successful development of full-size designs more rapidly. Verification of key requirements earlier in the development process may be possible, as well as validation and improvement of reliability because of more thorough evaluation of margins. Cost savings of development hardware are possible due to the use of smaller and lower flow rate hardware, resulting in reduced costs for manufacturing development hardware, reduced iterations of full-size hardware, and reduced testing costs. The latter is possible since the smaller, lower flow rate test facilities consume less propellant and require fewer test personnel. One method of scaling, discussed in this paper, however, may require higher pressure test facilities, which would negate some of these cost savings.

With so many potential advantages, why haven't scaling relationships been well defined after such a long time? One reason is that the number of physical and chemical processes - literally dozens - and their complex interrelationships in rocket engine combustion devices make clear and unambiguous relationships and interpretations difficult to obtain. As has been shown in many instances, maintaining full combustion similarity in rocket flow systems is practically impossible - there are simply too many conflicting requirements. This realization led to consideration of the notion of "partial modeling," or deliberately ignoring some of the similarity requirements depending upon the problem at hand. Also, these conflicting requirements required separate scaling concepts between steady and unsteady problems, so that the best scaled device to investigate performance and heat transfer was not necessarily the best device to investigate combustion stability.

Another reason for the lack of progress in scaling was the excessively compressed schedules to develop rocket engines in the 1950s and 1960s. The aerospace industry was in a great hurry to produce and use the rocket engines, and funding was widely available, so the development overwhelmingly proceeded with full-size devices at the full scale operating conditions. Design iterations, and even some of the basic research as well, were conducted with fullsize hardware. At the end of this period, and at great expense, rocket engine combustors were developed with acceptable performance, thermal margins, and stability margins. 
Research into scaling methods after this development period was also not widely conducted, due to a number of reasons: (1) high combustor efficiency had been achieved, eliminating the necessity to develop performance scaling rules; (2) combustion instability persisted mostly independent of performance considerations; and (3) computerintensive analyses became increasingly complex and inexpensive. ${ }^{2}$

Despite these historical advancements, there remains a desire today to develop new hardware that exceeds the previously demonstrated performance, with added requirements to reduce weight and cost, which may reduce thermal, stability, and structural margins. These improvements are partly due to new materials, new ideas, and the slow march of incremental research that points out that the previous engines can be made higher performing, lower weight, and more reliable. Unfortunately, LPRE development today is occurring during an era of significantly reduced budgets. Consequently, the development of new or novel concepts, or upgrades to previous designs, is occurring with the same painful process as used previously, except without the financing. A well-defined methodology for scaling would be as valuable today as it might have been 50 years ago, for performance as well as combustion stability, heat transfer, and ignition.

After 50 years of advanced development in the United States, what can be said about the scaling of combustion devices for LPREs and relationships to combustor performance, stability, compatibility, heat transfer, and ignition? Unfortunately, there is no "holy grail" of scaling yet defined, that will allow the development of large LPRE combustors to proceed directly from the information of small combustors. Yet there is still a path to determine the best method for this development.

The history of rocket engine research and development provides the design, fabrication, and test of thousands of different combustors. A compilation of the information from these devices can be considered a database for scaling. This database can be mined for information and cross references that can provide a significant step toward understanding important and useful scaling relationships. Each individual rocket engine company has kept track of some of its own data and information, but over time, with the change of personnel, much information has become lost. Capturing and using the historical information has become critical for the development of scaling relationships. An empirical correlation discussed in this paper, the Hewitt Correlation, is one such relationship. In addition to this hardware test database, another means is available in the current era of reduced budgets for research and development to investigate a large variety of influences to a far greater fidelity than previously possible. The use of combustion Computational Fluid Dynamics (CFD) for scaling development has become very encouraging.

This paper provides another link in a continuing effort to examine scaling on the basis of the historical data, as well as to use that data to define appropriate research and development programs when the opportunity arises. For this occasion, the emphasis will be placed upon examining the scaling of steady combustion and combustor performance efficiency. The focus will be on how that information can be used in combustor development. Thus, a brief review of the previous scaling studies will be conducted, followed by examination of a few examples from the historical database. This effort will lay the groundwork for future examinations of the scaling of transient rocket flows such as ignition, and unsteady rocket flows as present during combustion instability.

\section{Scaling of Combustion}

Scaling of combustion devices for LPREs was originally given substantial consideration starting in the 1950s in the United States, as found in a handful of well-referenced documents. ${ }^{1-13}$ A review of these documents and a modern assessment of scaling was conducted in the 1990s and recently published, ${ }^{14}$ while a more recent review is also available. ${ }^{15}$ Also, a recent examination of scaling from the specific viewpoint of combustion stability is available. $^{16}$

Scaling has been defined as "the ability to design new combustion devices with predictable performance on the basis of test experience with old devices."1,14 An updated definition of scaling would include design not only from old devices, but also from specialized test hardware, and not only using test experience, but also analysis. ${ }^{14}$ Some researchers have previously called this updated definition "modeling," "11 but that term is better left today to purely analytical treatments. Specialized test hardware, which can be larger or smaller, single- or multi-element, reacting or nonreacting, at different pressure or temperature, or something unique, can improve the means to successfully design new, full-scale, hardware. ${ }^{14-16}$ Some examples of scaling techniques recently published from Russia ${ }^{14}$ 
emphasized making the model or subscale hardware much simpler than the actual object to isolate the phenomenon under examination, a technique from partial modeling. ${ }^{11}$ Scaling methodologies are required to make use of test results of this specialized hardware for the design of the new hardware. Analysis can connect these test results to the new design, or even substitute for the testing itself. Thus, scaling techniques can be integrated throughout the design and development process, rather than used just as a point of departure.

\section{A. Exact Combustion Similarity for Steady Internal Aerothermochemistry}

Exact combustion similarity between two combustion flows in chambers of different sizes is a very rigorous requirement, implying that all component processes of combustion, although occurring at different scales, occur in identical fashion. ${ }^{4}$ Thus, the flow paths, flame patterns, locations and time histories of species generation and heat release, and contours of temperature, pressure, and velocity are geometrically similar, even though the actual scales may be different. ${ }^{4}$

A set of similarity parameters for steady internal aerothermochemistry in liquid propellant rocket engine combustion flows was obtained by Penner by writing the conservation equations for mass, momentum, and energy in non-dimensional form, and identifying the non-dimensional groups of parameters which multiply the dimensionless differential equations. ${ }^{1,5}$ This complete set of parameters for exact combustion similarity, for reacting multi-component gas mixtures neglecting radiant heat transfer and thermal diffusion effects, are: ${ }^{5}$

$$
\begin{aligned}
& \text { Reynolds number }=R e=\frac{\rho v L}{\mu} \\
& \text { Schmidt number }=S c=\frac{\mu}{\rho D} \\
& \text { Prandtl number }=\operatorname{Pr}=\frac{c_{p} \mu}{k} \\
& \text { Mach number }=M=\left(\frac{\rho v^{2}}{\nu^{2}}\right)^{1 / 2} \\
& \text { Froude number }=F r=\frac{v^{2}}{g_{a} L} \\
& \Phi=\frac{1 / 2 v^{2}}{\left(c_{p} / \gamma\right) T} \\
& \text { Specific Heat Ratio }=\gamma=\frac{c_{p}}{c_{v}} \\
& \text { First Damköhler Group }=D a, i=\frac{L}{v \tau_{i}} \\
& \text { Third Damköhler Group }=D a, i i i=\frac{q^{\prime} L}{v c_{p} T \tau_{i}}
\end{aligned}
$$

The first seven groups are familiar from nonreacting flow processes, and can be maintained constant even without chemical reactions in the system. The Reynolds number $(R e)$ is the ratio of inertial forces to viscous forces in the unit volume, the Schmidt number $(S c)$ the ratio of kinetic viscosity to molecular diffusivity, the Prandtl number $(P r)$ the ratio of momentum diffusivity to thermal diffusivity, the Mach number $(M)$ the ratio of kinetic energy of the flow to internal energy (or linear velocity to sonic velocity), and the Froude number $(\mathrm{Fr})$ the ratio of inertial forces to gravitational forces. 
Chemical changes in the flow processes are introduced by the two Damköhler groups. Da,i is the ratio of the rate of convection time $L / v$ to chemical time $\tau_{i}$, or the inverse ratio of specie generation by chemical reaction and the rate of removal by convection. Da,iii is the ratio of the rate of heat addition per unit volume by chemical reaction, $q^{\prime} / \tau_{i}$, and the rate of removal of heat by convection of enthalpy, $v c_{p} T / L$.

Constancy of all nine dimensionless groups for all processes between different sized combustion chambers assures that the steady aerothermochemical processes will be similar, since the different combustion flows would then be described by identical non-dimensional differential equations. Note that for fixed values of $\operatorname{Re}$ and $\operatorname{Pr}$, the Nusselt heat transfer number is constant, so that the boundary conditions corresponding to heat transfer to chamber walls introduces no new similarity parameter. ${ }^{5}$ It is also important to realize that many of the dimensionless numbers occur multiple times in the equations, because they appear in multiple processes. The $R e$, e.g., must be maintained for individual injection element flows as well as core flows and boundary layer flows in the combustion chamber. Also, note that this particular list of parameters does not necessarily apply to transient or unsteady processes.

Even with steady aerothermochemistry, the number of processes occurring in liquid rocket combustors is so large, scaling of these reacting flows with complete similarity is found to be practically impossible. ${ }^{4,5}$ There are so many simultaneous constraints on the similarities between scales that it is simply impossible to satisfy them all at the same time. Many of the similarity parameters require opposable requirements. Even extensive simplifications of the number of processes and required similarities, as will be discussed below, do not allow for reasonable solutions. And even the list shown may not include all the critical processes. It has been argued that additional parameters may be required for phenomena involving the liquid phase. ${ }^{17}$

\section{B. Partial Modeling}

Given these formidable initial obstacles, Penner ${ }^{5}$ and Crocco $^{6}$ concluded that reasonable conjectures about scaling procedures would be possible only by classifying the physicochemical processes of the combustion into ratecontrolling chemical reaction steps, and including only the dominant processes, disregarding the others for engineering purposes. Such tactics are defined in discussions of partial modeling. ${ }^{11}$

By assuming homogeneous, low velocity flow systems without significant external forces, which are reasonable assumptions for the head end of a combustion chamber, Penner reduced the required set of similarity parameters for assuring similar steady combustion processes to five groups: $R e, S c, P r, D a, i$, and $D a, i i i{ }^{5}$ These five groups are equivalent to Damköhler's original five criteria for assuring dynamic and reaction-kinetic similarity in low velocity flows without external forces and without heat loss to the chamber walls. ${ }^{5}$

For a given propellant system with fixed injector temperature, the important similarity groups for steady internal aerothermochemistry reduce to $R e$ and $D a, i,{ }^{8}$ while $M$ may become important for high-velocity flow processes involving oscillations, ${ }^{8}$ and, as will be shown, in combustion chambers with coarse element patterns.

For practical scaling laws in combustion flows, the critical variable is found to be the chemical conversion time $\tau_{i}$. Based on the functional form assumed for $\tau_{i}$, a variety of scaling rules for liquid rocket engine combustion chamber geometries can be devised. ${ }^{1,5,6,8,9}$ Two of the early methods defined by Penner and Crocco will now be discussed. The comparisons will be made between a "fullscale" combustor and a "subscale" combustor, where it is assumed the fullscale is the physically larger and has higher thrust.

\section{The Penner-Tsien Scaling Rule}

An example of the attempt to scale using the methods described by Penner ${ }^{5-9}$ is now provided. Penner assumed that chamber pressure be maintained constant, so that $\tau_{i}$ increases with the square of the engine thrust or the square of the dimensions. ${ }^{9} \quad$ By assuming the two combustors use identical physicochemical properties (propellant chemistry, propellant inlet temperatures, flow mixture ratios, etc.), the $S c$ and $\operatorname{Pr}$ are maintained constant. Also, since $q^{\prime}, c_{p}$, and $T$ likewise do not vary, then Da,iii is constant if $D a, i$ is constant. Thus, the five groups in [5] are reduced to two, $R e$ and $D a, i$. Even with such dramatic simplifications, the competition between $R e$ and $D a, i$ will demand perplexing requirements. 
With the chamber pressure constant, combining $R e$ and $D a, i$ results in

$$
\left(\frac{\tau_{i, S}}{\tau_{i, F}}\right)=\left(\frac{L_{S}}{L_{F}}\right)^{2}
$$

Equation (10) describes a situation such that, at constant chamber pressure, chamber temperature, and propellant properties, as the length scales are reduced, the chemical conversion times must be reduced as the square of the length scales. Thus, e.g., if the subscale is half the size of the fullscale, then the chemical conversion times in the subscale must be $1 / 4$ the fullscale. It is not obvious how this is required to happen.

Note that to maintain the $R e$ constant at constant pressure, then

$$
\left(\frac{v_{S}}{v_{F}}\right)=\left(\frac{L_{F}}{L_{S}}\right)
$$

and to maintain continuity through the injector elements,

$$
\left(\frac{d_{S}}{d_{F}}\right)=\left(\frac{L_{S}}{L_{F}}\right)
$$

Thus, the velocity increases as the length scales are reduced, while the injector dimensions scale proportionally to the length scales. In the example of the half-size subscale, the velocities in the subscale must be twice the fullscale. Thus, the flow rate through the subscale must be increased (by increasing the pressure drop across the injector) since, as in the example, the half-size injector would normally flow only $1 / 4$ the flow rate of the fullscale. Thus, while these conditions force $R e$ and $D a, i$ to match, the $M$ in the chamber is no longer constant (to increase the relative flow rate in the subscale at constant pressure).

This scaling relationship, called by Crocco the "Penner-Tsien Rule," essentially requires the subscale operate at the same pressure and temperature as the fullscale, but increase the injection velocities inversely proportional to the scale factor. Certainly the higher injection velocities will reduce the chemical time scales, but is it sufficient to change it by the square? Penner concluded additional control was required, such as from the addition of surfactants in the propellant composition to change the surface tension and hence the droplet size in the combustion sprays. This is a formidable requirement when little is really understood about the functional form of atomization and vaporization on the reaction rate.

\section{The Crocco Scaling Rule}

Crocco used a different approach than Penner, but in his "second rule" similarly encountered the competition between $R e$ and $D a, i .{ }^{9} \quad$ Crocco assumed $\tau_{i}$ was inversely proportional to some power of chamber pressure, generating a scaling rule that preserves combustion similarity and $R e$, but not $M$, causing dimensions and thrust to scale with chamber pressure as a function of that power. ${ }^{6}$ The significant differences from the Penner-Tsien rule

were the decision not to maintain constant pressure, and assuming that $\tau \sim 1 / p^{m}$, or the chemical times inversely proportional to pressure to some power. These considerations result in

$$
\left(\frac{\tau_{i, S}}{\tau_{i, F}}\right)=\left(\frac{L_{S}}{L_{F}}\right)^{2 m /(m+1)}
$$

and

$$
\left(\frac{v_{S}}{v_{F}}\right)=\left(\frac{L_{S}}{L_{F}}\right)^{(1-m) /(1+m)}
$$


and

$$
\left(\frac{d_{S}}{d_{F}}\right)=\left(\frac{L_{S}}{L_{F}}\right)^{m /(m+1)}
$$

and

$$
\left(\frac{p_{S}}{p_{F}}\right)=\left(\frac{L_{F}}{L_{S}}\right)^{2 /(m+1)}
$$

Thus, e.g., if $m=1$ (i.e., $\tau \sim 1 / p$ ), then

$$
\begin{aligned}
& \left(\frac{\tau_{i, S}}{\tau_{i, F}}\right)=\left(\frac{L_{S}}{L_{F}}\right) \quad \text { and } \quad\left(\frac{v_{S}}{v_{F}}\right)=1 \quad \text { and } \\
& \left(\frac{d_{S}}{d_{F}}\right)=\left(\frac{L_{S}}{L_{F}}\right)^{1 / 2} \text { and } \quad\left(\frac{p_{S}}{p_{F}}\right)=\left(\frac{L_{S}}{L_{F}}\right)
\end{aligned}
$$

These equations describe a situation such that, at constant chamber temperature and propellant properties, as the length scales are reduced, the chemical conversion times must be reduced in proportion, while the velocities are equal and, most importantly, the pressures are increased. The injector elements are distorted by the square root of the scale. Thus, e.g., if the subscale is half the size of the fullscale, then the injector element dimensions are reduced by the square root of 2 and the chemical conversion times in the subscale must be half the fullscale. The pressures, on the other hand, are doubled.

\section{Conclusions of 1950s Scaling Studies}

The paths defined by both Penner and Crocco lead to challenging design requirements, and, frankly, very uncertain practices and non-intuitive distortions between the subscale and fullscale hardware. The challenge is undoubtedly to understand how to model the chemical conversion time, $\tau_{i}$, or even to determine the rate-controlling steps, which will require a thorough examination of the physical and chemical processes of combustion in LPRE combustors. Certainly such misgivings were just another reason preventing the use of these scaling techniques during the formative years of the late 1950s through the 1960s, when the vast majority of research and development of LPREs in the United States was conducted. Only time will tell whether these techniques were practiced elsewhere, such as in the former Soviet Union.

LPRE combustor development itself to date has provided no conclusions to these assumptions. As previously mentioned, early development of LPRE combustors was well funded, rapid, and intensely empirical, so stable and efficient designs were created in a relatively short time and at great expense, using full-scale hardware almost exclusively. Even later, less well-funded engine development programs - to regulate costly test programs - had little incentive to change these developed and successful designs, even though applications were often considerably different. It is the current generation of LPRE developers which may use this database and analytical tools to investigate the scaling relationships.

\section{Scaling of Performance}

Relating combustion performance between different sizes of combustion devices is probably the least complex problem among all scaling processes, compared to such challenges as ignition, heat transfer, and combustion instability. While this scaling may be straightforward, that does not mean it is simple, especially in the current era when performance is often required to be higher than previously demonstrated. 


\section{A. Performance Subelements}

The various subelements that comprise LPRE combustor performance will be identified in this section. These various subelements have been previously defined in a number of widely available documents. ${ }^{18-20}$ For this discussion, the focus is on the combustor performance upstream of the throat - i.e., the energy release efficiency, which is still poorly predicted a priori. Performance losses in the nozzle downstream of the throat are fairly well characterized by analytical means. ${ }^{19}$

Combustion performance losses in LPRE combustion devices - i.e., in the combustion chamber - can be broken down into five basic categories:

1. Collective (multi-element) inefficiency of all core elements

2. Collective (multi-element) inefficiency of all barrier elements

3. Surface boundary losses

4. Unintentional maldistribution of mass and velocity across the injector face

5. Intentional maldistribution of mass and velocity across the injector face.

The collective inefficiencies of the core and barrier can be further broken down into the following parts:

a) Single element mixing inefficiency for each element type

b) Single element vaporization inefficiency for each element type

c) Inter-element mixing inefficiency (or the multi-element mixing inefficiency, which is the sum of single element mixing inefficiencies modified by element interactions)

d) Inter-element vaporization inefficiency (or the multi-element vaporization inefficiency, which is the sum of single element vaporization inefficiencies modified by element interactions)

e) Losses due to two-dimensional effects of the flowstream

f) Losses due to reaction kinetics

g) Losses due to the radiation energy from various combustion species

The surface boundary losses, which can be included in the collective efficiency of the barrier, or, more handily, kept separately, include the following:

a) Heat energy losses from the fluids to the injector and chamber walls

b) Boundary layer losses (effect of wall boundaries on the flow streams)

Heat exchange between the products in the combustor and the fluids in the injector is usually not modeled, because this process is internal within the control volume of the injector inlet and the combustion chamber exit. However, heat exchange between the products in the combustor and the fluids in the coolant jacket of the combustion chamber may or may not be included, depending upon the definition of the control volume.

Unintentional maldistribution losses are due to:

a) Non-uniform mass, velocity, and pressure distributions at the injector inlets

b) Non-uniform mass, velocity, and pressure distributions resulting from the injector manifolding

c) Manufacturing tolerance variations on injector metering features

Intentional maldistributions losses are due to:

a) Fuel film coolant (FFC) injected into the chamber periphery

b) Deliberate mass flow rate bias of various elements across the injector face (mixture ratio bias)

c) Local element mass flow bias (e.g., off-set, angled or scarfed coaxial post)

d) Deliberate burning rate variations across the injector face, due to different elements used in the pattern

All combustors include some form of almost all of the first four categories of losses. The fifth category can be controlled to a large extent. The JANNAF rigorous procedure suggests that, using the prescribed methodology, 
performance can be calculated a priori within $1 \%{ }^{18}$ In the past, this variability was acceptable. Injector designers today know that many applications require performance efficiencies in excess of $99 \%$, while the number of allowable design iterations is minimal, putting the JANNAF predictability in question as well as the capability to measure as accurately.

\section{B. Influence of the Combustion Chamber Geometry}

Certain aspects of the combustion chamber geometry influence the performance comparison between scales. For example, one chamber can be shorter than the other, or use a shorter cylindrical section, or have a different $L^{*}$. The use of a scaled combustion chamber is to allow the designer to predict the full-size thrust chamber (injector and chamber system) performance and its sensitivities. The two most important features of the combustion chamber are its length and its shape.

\section{Chamber Length}

The length of the combustion chamber, from the injector face to the geometric throat plane, affects the overall vaporization efficiency of liquid and two-phase propellants, and the overall mixing efficiency. For vaporizationlimited combustion, increasing chamber length will increase the overall performance until sufficient length is available to complete vaporization of all propellants. For mixing-limited combustion, increasing chamber length can increase the overall performance but often at a much slower rate, depending upon the element design. Large (or "coarse") elements, or elements that have less initial interpropellant mixing (such as many impinging element patterns), show a mixing improvement with increased length. Small (or "fine") elements, or elements that have more initial interpropellant mixing (such as many coaxial element patterns), show little mixing improvement with increased length.

\section{Chamber Contraction Ratio}

The contraction ratio defines the mean value of $M$ in the combustion chamber, and affects the mean level of mixing in the developing combustion flow field.

\section{Chamber Barrel Length}

The shape of the combustion chamber, and specifically the length of constant diameter sections before the start of convergence in the nozzle, affect the vaporization, mixing, and heat transfer profiles. Depending upon the element axial energy release rate, the chamber geometry at the head end of the combustion chamber can have a profound effect on overall performance (as well as heat transfer and combustion stability).

\section{Chamber Characteristic Length}

The $\mathrm{L}^{*}$ is a relativistic parameter that relates back to the residence or "stay" time of propellants in the combustion chamber, $\tau_{\mathrm{r}}{ }^{20}$ To achieve combustor performance in excess of $99 \%$, other factors usually play a larger role.

\section{Influence of the Injection Element}

Undoubtedly, the injection element itself has the most influence on the characteristics of performance, heat transfer, combustion stability, and ignition.

One of the first and most obvious relationships between a full-size combustor and a subscale test article is to decide what size of element to use. The Penner-Tsien rule described above used element dimensions proportional to the scale, shown in Eqn. (12), while Crocco's second rule had a distortion of the element geometry as described by Eqn. (15).

Another key feature to describe is whether there is any element-to-element interaction. Consider a multi-element injector with many hundreds of elements. Any multi-element interaction can be designated as $X_{\text {ia }}$, where, for example, the relationship between full-size and subscale characteristic exhaust velocity performance is $\eta_{C^{*}, f}=$ 
$X_{i a, s s}{ }^{*} \eta_{C^{*}, s}$, or the relationship between full-size and single element characteristic exhaust velocity performance is $\eta_{C^{*}, f}=X_{i a, s e}{ }^{*} \eta_{C^{*}, s e}$. While coaxial elements have been described to have virtually no interaction ${ }^{14}$ (i.e., $X_{i a}=1$ ), impinging element patterns not only have some level of interaction but often rely on it. It is certainly not clear that $X_{i a}$ is a constant value between scales. Comparison between single element performance and multi-element performance, where other aspects (such as heat loss to the combustion chamber walls) have been removed, is one way to determine $X_{i a}$.

\section{Two Common Scaling Methods}

There seem to be two methods in current practice used to scale full-size combustors with small-sized hardware: 1) using identical injector elements, and 2) using photo-scaled injector elements.

\section{Identical Injector Elements}

The first method simply uses the exact same injector element geometry in the small-size combustor as found in the full-size combustor, as depicted in Fig. 1. Thus, the energy release characteristics (subdivided generally into atomization, vaporization, mixing, and reaction) can be made identical, depending upon aspects of the combustion chamber geometry. While this method has advantages for performance scaling, to be discussed, the use for combustion stability scaling is to be approached with caution. ${ }^{14}$

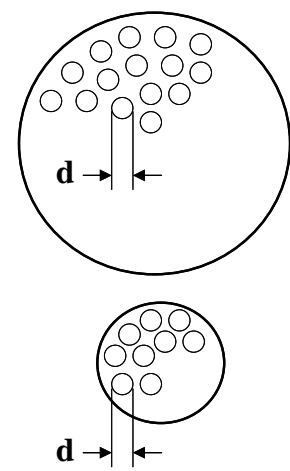

Figure 1. Scaling with constant injector element dimensions.

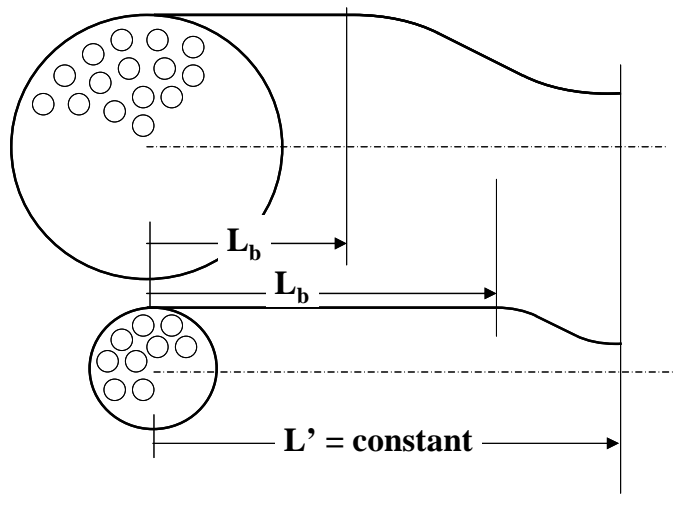

Figure 2. Comparison of typical combustion chambers used in scaling with constant element dimensions. $L_{b}$ is not constant.

Note that these energy release characteristics are not scaled in the sense as described earlier. The Re of the injector features in the small-size chamber are exactly the same as the $R e$ of the injector features in the full-size chamber. The Re of the combustion in the small-size chamber may or may not be similar to the $R e$ of the combustion in the full-size chamber, depending upon chamber geometry similarity.

How can combustion chamber geometrical features influence the performance (along with heat transfer and combustion stability) in a small-size chamber? The typical chamber profile used in small-size hardware is depicted in Fig. 2, and compared to the typical full-size chamber. The subscale geometry is usually defined by requirements to maintain the same L' and the same contraction ratio as the full-size chamber. Keeping the L' constant primarily maintains similar first-order vaporization and mixing efficiencies, while keeping the contraction ratio constant retains at least the $M$ at the head end of the chamber. Also of consideration is manufacturing a shorter and hence less expensive throat section for the subscale.

Figure 2 displays a difference in the convergence profile from the near-head end region to the near-throat region between full-size and subscale, resulting in different $M$ profiles. If this occurs in the region where the energy release rate is still changing dramatically, then the performance, even with the same injector elements, can be quite different. The influence is obviously most profound with coarse injector elements (elements with larger flowratesper-element). An example of the potential differences between two typical chambers is shown in Fig. 3. 


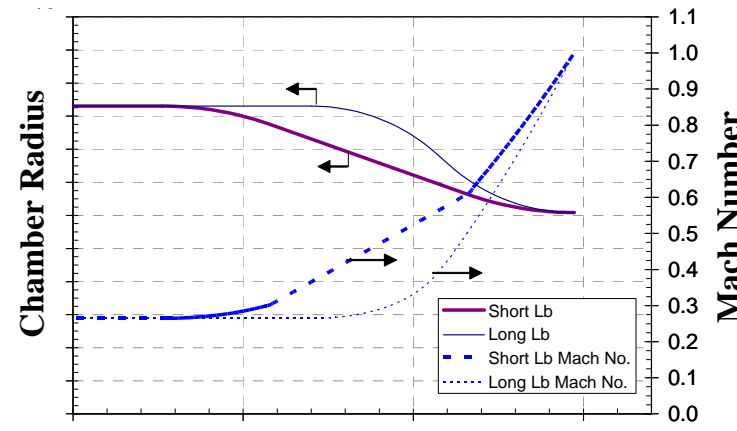

Distance from Injector Face

Figure 3. Typical change of $M$ with varying $L_{b}$.

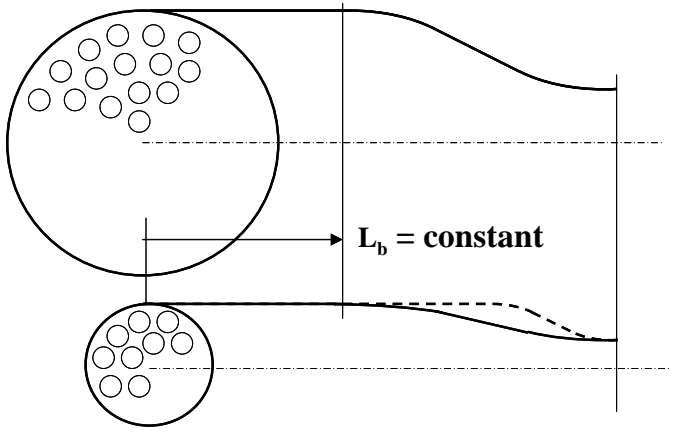

Figure 4. Subscale chamber with constant $L_{b}$ and M.

One way to correct this difference is match the convergence profile $\left(A_{c h} / A^{*}\right)$ over the whole length of the combustion chamber, as shown in Fig. 4. This correction will result in chambers with different convergence angles. Note that even single element injectors can be installed in combustion chambers with constant $M$ profiles. This method is not typically used because of the increased manufacturing costs of the nozzle sections. Ross did not recommend this method as a general scaling rule because of the potential for excessive convergence angles and hence lower throat $\mathrm{C}_{\mathrm{d} .}{ }^{10}$ In general, however, this is not likely to be a problem unless the chamber diameter difference is very large, in excess of 5 times.

\section{Photo-scaled Injector Elements}

The second method uses a photo-scaled injector in the small-size combustion chamber, meaning that all injector dimensions are changed in proportion to the combustion chamber length scales, as depicted in Fig. 5. This method is not similar to either of the two scaling laws presented earlier. While the injector dimensions scale as per Eqn. (12), to maintain constant chamber pressure the injection velocities must be made constant between scales, which is different than prescribed by Eqn. (11). If the injection velocities in the small-size combustor are increased, by increasing the mass flow rate through the injector, then the chamber pressure will increase because the chamber throat diameter has already been fixed. Thus, $R e$ in the injection elements are not constant between the scales, and $R e$ in the combustion chamber are not constant.

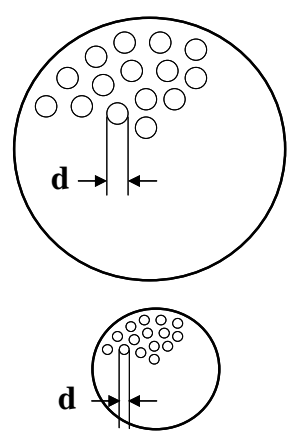

Figure 5. Scaling with photo-scaled injector element dimensions.

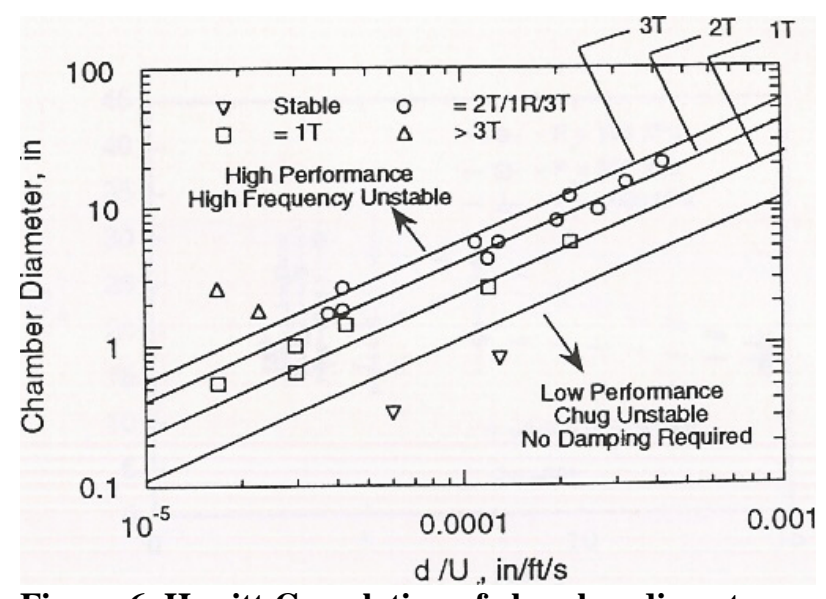

Figure 6. Hewitt Correlation of chamber diameter versus injector characteristic $d / V^{21}$

This method is suggested from empirical combustion stability data originally compiled by Hewitt, and first published openly in [21], and since discussed in many forms, including most recently [22]. A typical plot of the Hewitt Correlation is shown in Fig. 6. ${ }^{21}$ This plot compares the chamber diameter and the ratio of the injector element diameter over the injector element velocity for the least volatile propellant. While this correlation was 
developed for combustion stability, it also separates performance effects for like-on-like doublet elements, as shown, with higher performance in the upper left and lower performance in the lower right.

For combustion stability, Fig. 6 suggests that changing the $d / V$ characteristic in relation to the combustion chamber diameter maintains a constant combustion stability margin. Thus, this rule is essentially

$$
\left(\frac{d_{S}}{d_{F}}\right)\left(\frac{v_{F}}{v_{S}}\right)=\left(\frac{D_{c, S}}{D_{c, F}}\right)
$$

Thus, if the small-size chamber diameter is made $1 / 2$ of the full-size chamber diameter, i.e., $D_{c, S}=1 / 2 D_{c, F}$, then either the injector orifice diameter is to be halved or the injection velocity doubled, to maintain similar stability characteristics. A reduction in element dimensions proportional with the chamber diameter reduction, while maintaining constant injection velocity and constant chamber pressure, is one example of a photo-scaled combustor. This results in an injector design that is photographically reduced in relation to the chamber diameter, as depicted in Fig. 5.

What remain to be determined are the suitable chamber length dimensions. Should the chamber lengths (barrel and nozzle) be photographically reduced as well, or is there some other relation? This is not obvious, since the injector and chamber $R e$ are not the same between scales.

For performance, clearly the photographically reduced smaller injection element will require less L' (and less $\mathrm{L}^{*}$ ) than the larger element. Without changing the injection velocities or the chamber velocities (essentially keeping chamber pressure constant), the contraction ratios will be the same, and at least the head-end $M$ will be the same. Both injection and chamber characteristic Re will be reduced from the larger chamber by the scale ratio, which means that atomization, vaporization, mixing, and probably reaction characteristics (i.e., the composite energy release rate) will be relatively worse in the smaller combustor (i.e., burning processes will take longer) than had the injection and combustion Re been matched with the smaller injector diameters. Thus, it is equally clear that the smaller injection element will require more L' (and more $\mathrm{L}^{*}$ ) than the photographically reduced chamber parameters. The distinction, illustrated in Fig. 7, is not yet defined and requires further elaboration.

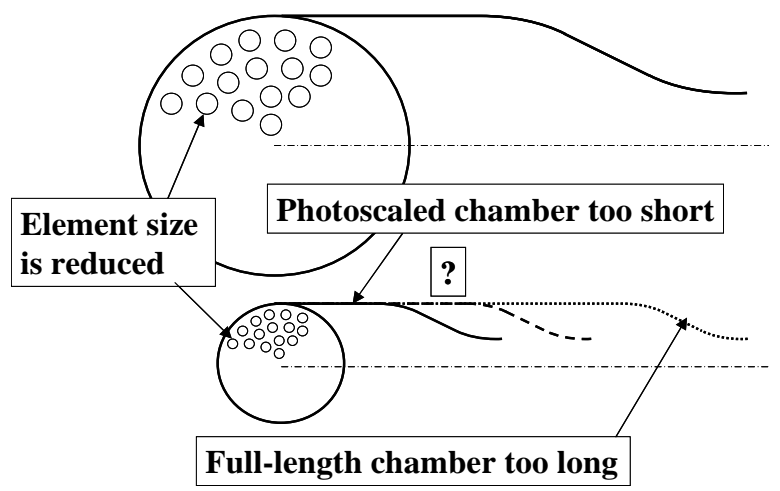

Figure 7. Photo-scaling the combustion chamber with a photo-scaled injector.

Hewitt suggested another methodology to compare photoscaled combustors, ${ }^{23}$ derived from the Priem and Heidmann generalized length correlation. ${ }^{24}$ The liquid propellant vaporization rate according to Priem and Heidmann is inversely proportional to the mass median liquid droplet radius $r_{m}$ to the 1.45 power. ${ }^{24}$ The relationship between injector element orifice diameter $\mathrm{d}$ and mass median liquid droplet radius depends on the element type. Priem and Heidmann suggest that for impinging injector elements, $\mathrm{r}_{\mathrm{m}}$ is proportional to d. Thus, if the injector is photoscaled to $1 / 2$ of the full-size injector, the element is $1 / 2$ the full-size diameter and the droplet size is $1 / 2$ the fullsize droplet size, then the vaporization rate is 2.7 times faster in the smaller chamber with the smaller element than with the larger element in the larger chamber, i.e., the vaporization rate is relatively better in the smaller combustor by a factor 2.7 / 2 , so the vaporization efficiency is relatively better in the smaller chamber. 
This is not universal for all injector elements, since not all injector elements have relationships where liquid droplet size is directly proportional to element diameter. For the proportionality of vaporization rate to the mass median liquid droplet radius $\mathrm{r}_{\mathrm{m}}$ to the 1.45 power, the mass median liquid droplet size must have a proportionality exponent greater than 0.69 relative to injector orifice diameter or the smaller chamber will have a proportionally worse vaporization rate. For example, Priem and Heidmann suggest for parallel jets (showerhead orifices) that the orifice diameter is proportional to the droplet size to the 0.67 power. Thus, if the injector is photoscaled to $1 / 2$ of the full-size chamber, the element is $1 / 2$ the full-size element diameter and the droplet size is 0.63 the full-size droplet size, then the vaporization rate with the smaller element in the smaller chamber is 1.96 times faster than with the larger element in the larger chamber, i.e., the vaporization rate is relatively worse in the smaller combustor by a factor 1.96 / 2, so the vaporization efficiency is relatively worse in the smaller chamber. Lefebvre shows that for plain-orifice atomizers, the proportionality constant can range from 0.3 to $1.2,{ }^{25}$ a wide range around the Priem and Heidmann value of 0.67 . For pressure-swirl atomizers, Lefebvre suggests the proportionality constant is about $0.5,{ }^{25}$ which suggests the vaporization rate of swirl coax injectors will be relatively worse in the photoscaled combustor.

\section{E. Use of Non-Similar Scales in the Two Common Methods}

Both the identical-element and photo-scaled-element scaling methods use elements that are not properly scaled to the combustion chamber according to the methods described by Penner or Crocco. For combustion and performance, the identical-element method is preferable because the injector parameters (defined by $R e$, etc.) practically match the fullscale, and with proper geometry, the $M$ can match as well. As will be shown, this method has been preferred in development programs to date. However, the photo-scaled-element scaling method offers the advantage of combustion stability information from the scaled combustor test. Can combustion and performance information be meaningful from this test as well ?

The answer is shown by consideration of the regimes in which the scaling is taking place. While the element $R e$ (and Weber Number We) are decreasing as injector diameter $d$ is decreasing, perhaps the energy release processes actually do not change dramatically over the scaling range to make substantial differences. Investigations into the effect of scaling on the individual LPRE combustor processes of injection, atomization, vaporization, mixing, and reaction are required. A significant, research-oriented evaluation of scaling of LPRE combustion devices will eventually require evaluation of all these individual processes as well as their interactions. Some of these investigations are in progress. ${ }^{26}$ For example, it is well known that liquid jets in LPRE combustors operate in turbulent regimes many orders of magnitude above transitional or laminar regimes, and atomization occurs in the fully atomized regime many orders of magnitude above other atomization regimes. ${ }^{26}$ One study of scaling of the primary atomization of LRPE liquid coaxial jets, reproduced in Fig. 8, shows just how far the separation between normal operation, or even dramatically scaled operation, and changes to the regime of primary atomization lies. The point is clear that the form of primary atomization for these dramatically scaled elements will change little, if at all, from their nominal operating points.

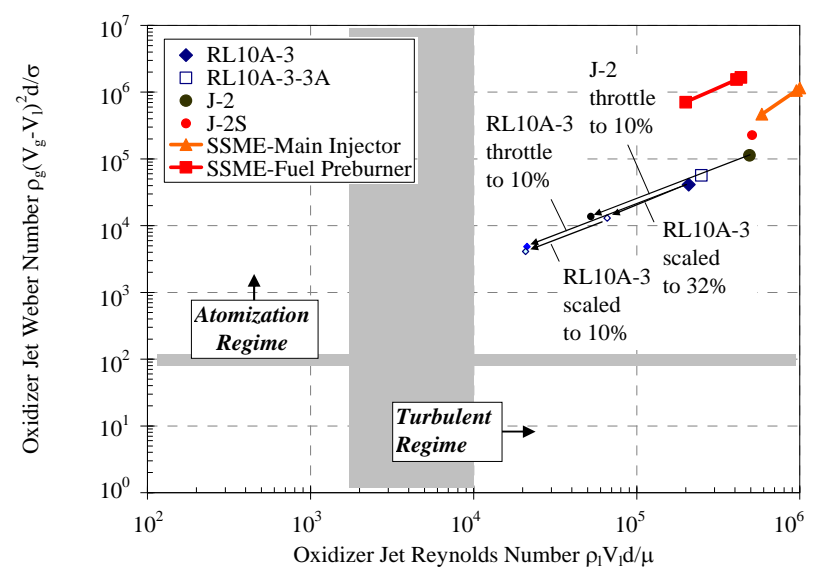

Figure 8. Comparison of jet $R e$ and aerodynamic jet We and typical O2/H2 LPRE coaxial injector elements. ${ }^{26}$ 
Obviously this photo-scaling has limitations - the dimensions can only be reduced so far before characteristics do change dramatically. Some examples of available scaling range are evident from development of microthrusters. ${ }^{27,28}$ However, the operable range of the Hewitt Correlation ${ }^{21,22}$ suggests that the useful range for photo-scaling can be quite practical.

\section{Historical Case Studies}

It is now informative to revisit some of the historical development programs where notions of scaled hardware were used, and evaluate the results from the perspective of performance. Note that for some of these programs, scaling of performance was only one of many considerations; often, efforts to derive information about combustion stability and heat transfer were as much if not more important in the scaled device.

\section{A. M-1}

Probably the first recognition of the importance of using scaled hardware during development was with the M-1 engine, the largest liquid oxygen/hydrogen engine conceived in the United States. This 6670-kN (1,500 Klbf) thrust engine was an upper stage concept considered for Apollo and other missions, but was terminated in advanced component development. ${ }^{29}$ While the injector was uncommonly large (106.7 cm (42") diameter), and similar in size to the F-1 engine injector, the less frantic schedule allowed a subscale methodology to be included during development that the F-1 program did not attempt. ${ }^{30}$ The use of small-size hardware provided optimization of the performance and some of the combustion stability characteristics. Characteristics of the fullscale combustor that were matched in the subscale combustor were element geometries, element-to-element spacing, chamber length (L'), chamber contraction ratio, and chamber pressure. ${ }^{30,31}$ The baseline element type was shear coaxial.

The M-1 is an interesting case study because of the gigantic size difference between the fullscale and subscale hardware. The full-size M-1 injector is shown in Figs. 9 and 10. The small-size subscale hardware is shown in Figs. 11 and $12 .^{31}$ A comparison of the combustor hardware to scale is shown in Fig. 13. Note that the subscale injector size approximates one of the fullscale injector baffle pockets, a relationship that has implications to combustion stability scaling.

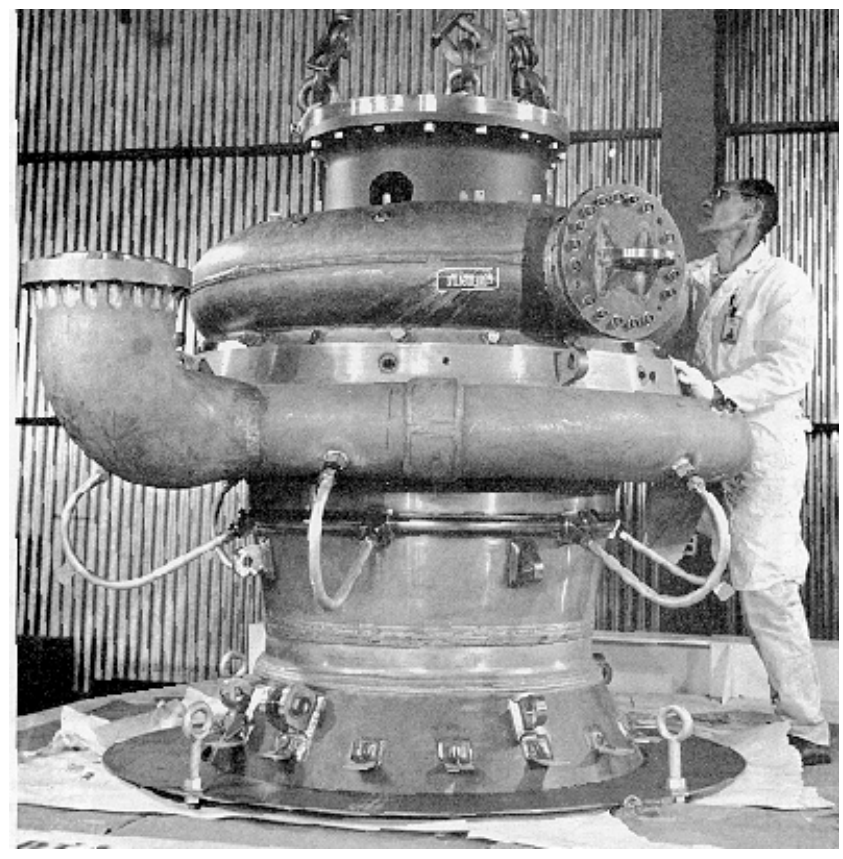

Figure 9. Fullscale M-1 combustion chamber.

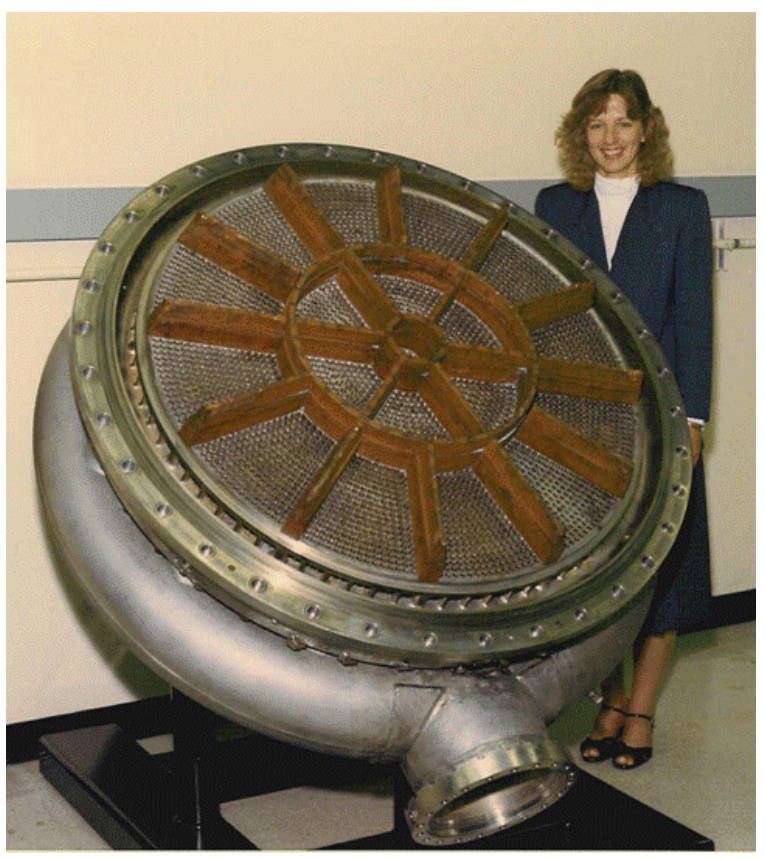

Figure 10. Fullscale M-1 injector. 


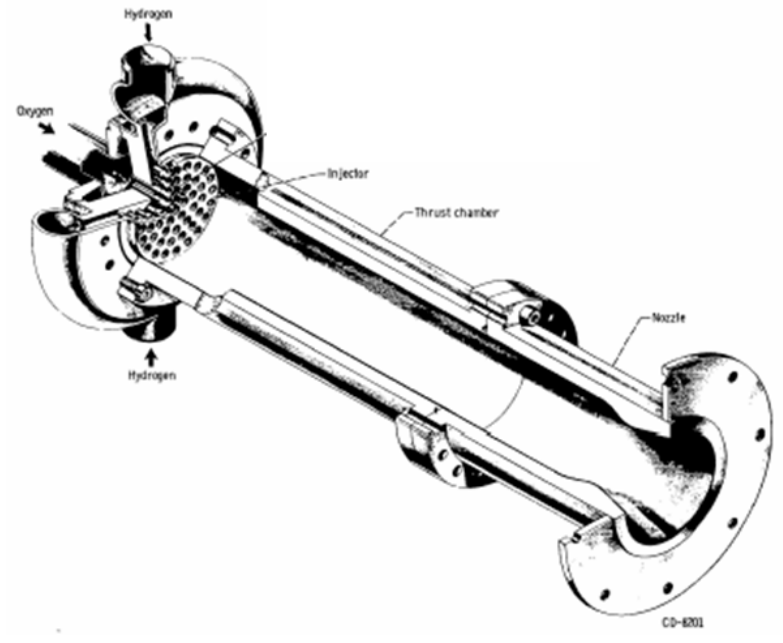

Figure 11. Subscale M-1 combustion chamber. ${ }^{31}$
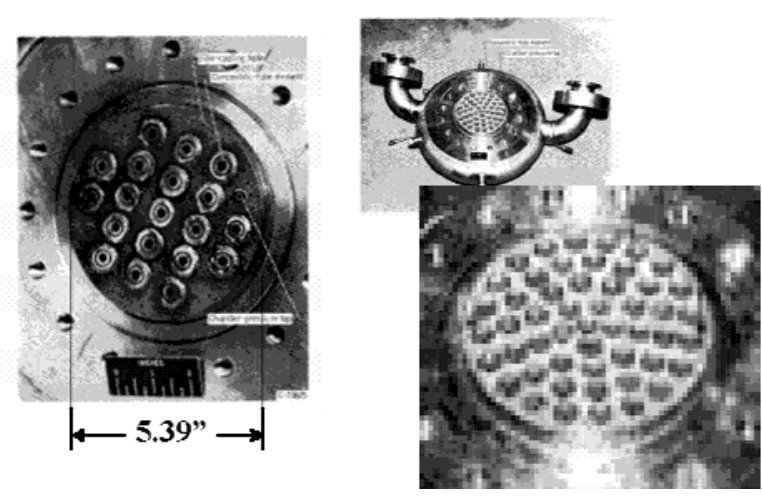

Figure 12. Subscale M-1 injectors. ${ }^{31}$

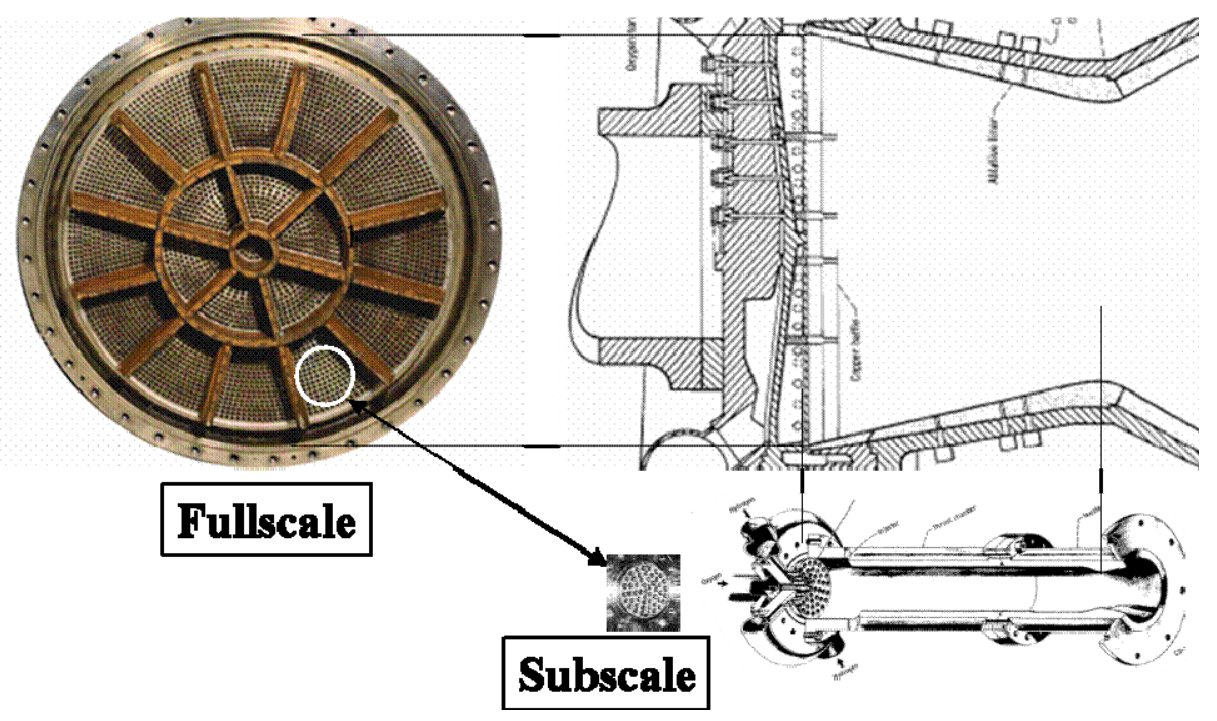

Figure 13. Size comparison of M-1 fullscale and subscale combustors, shown to scale. ${ }^{29,31}$

A comparison of the measured $\eta_{\mathrm{C}^{*}}$ of the subscale to the fullscale is shown in Fig. $14 .{ }^{30}$ At the design mixture ratio of 5.5, 99.3\% $\eta_{\mathrm{C}^{*}}$ efficiency was measured in the subscale while $96.0 \%$ was measured in the fullscale. To what is subscribed the rather large difference in performance between these combustors?

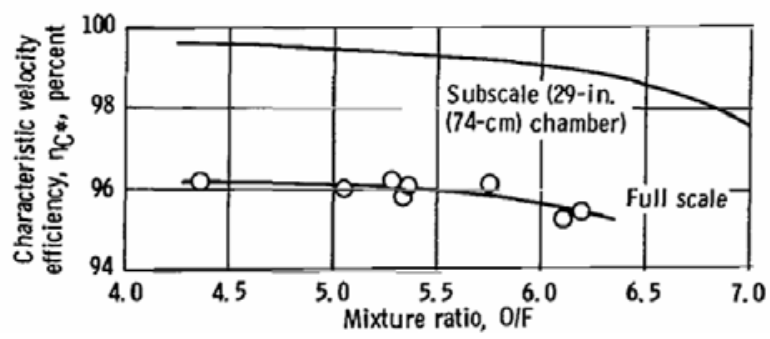

Figure 14. $\eta_{\mathrm{C}^{*}}$ comparison of $\mathrm{M}-1$ fullscale and subscale combustors. ${ }^{27}$ 
The first difference is the obviously large differences in intentional maldistributions necessary to cool the walls and baffle surfaces. A simple streamtube mixing analysis as described in [32] suggests the difference in intentional maldistribution of the fullscale explains about $1.8 \%$ of the $3.3 \%$ difference. A second difference is that the elements adjacent to the baffles, which constituted $23 \%$ of the total number of elements, were subjected to a mechanical distortion of the round oxidizer exit orifice, in an effort to further protect the baffles from thermal distress. While there is no exact calculation available, an estimate of the mixing loss due to this change explains about another $0.6 \%-0.8 \%$ of the $3.3 \%$ difference. Third, both injectors used Rigimesh, a porous sintered metal, as the faceplate material, but there were no real differences in loss due to face cooling. Finally, note that the subscale combustor included a long straight barrel section, while the fullscale chamber was conical starting from the injector face. The axial combustion profile was thus subjected to different Mach number profiles as well as different L*. A calculation of this difference using [32] explains about $0.3 \%$ of the variation.

The summation of the explained differences leaves about $0.4 \%-0.6 \%$ of the variation unexplained, which is similar to a typical expected measurement error of $0.5 \%$. However, one final difference may be attributable to unintentional maldistributions, which can be quite large in large hardware. The M-1 is one of the largest diameter injectors ever tested, and supplying mass flow uniformly to every element across the injector face would certainly be a challenge. The liquid oxygen was supplied from a single inlet which creates a single point source for the flow. This problem was alleviated by a constant-velocity torus and relatively low dynamic pressures in the distribution network compared to the metering pressure drops. The cold gaseous hydrogen was also supplied from a single inlet (for tests with the ablative chamber), from where it flowed into an annular torus, through cross feeds, and into another manifold at the chamber periphery, and then into the injector cavity and radially through the forest of oxidizer posts before turning 90-degrees and exiting the face. The dynamic pressures are higher for this circuit, and it is likely there are maldistribution losses here. CFD is capable today of making reliable predictions of these losses.

\section{B. Space Shuttle Orbital Maneuvering Engine}

The Space Shuttle Orbital Maneuvering Engine (OME), originally developed in the early to mid-1970s, continues to fly today on the United States Space Shuttle. ${ }^{33}$ This $26.7 \mathrm{kN}$ (6 Klbf) thrust engine uses nitrogen tetroxide and monomethylhydrazine $\left(\mathrm{N}_{2} \mathrm{O}_{4} / \mathrm{MMH}\right)$ propellants at a mixture ratio of 1.65 and chamber pressure of $0.86 \mathrm{MPa}$ (125 psia), in a chamber diameter of $20.6 \mathrm{~cm}\left(8.11\right.$ ”). ${ }^{33,34}$ Hardware is shown in Fig. $15^{33}$

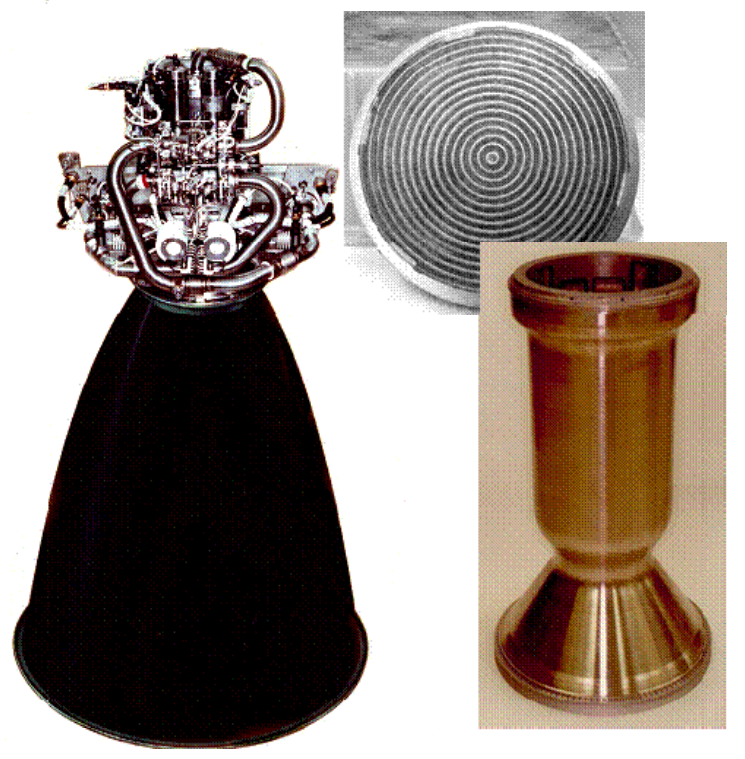

Figure 15. OME engine, injector, and combustion chamber hardware. ${ }^{33}$

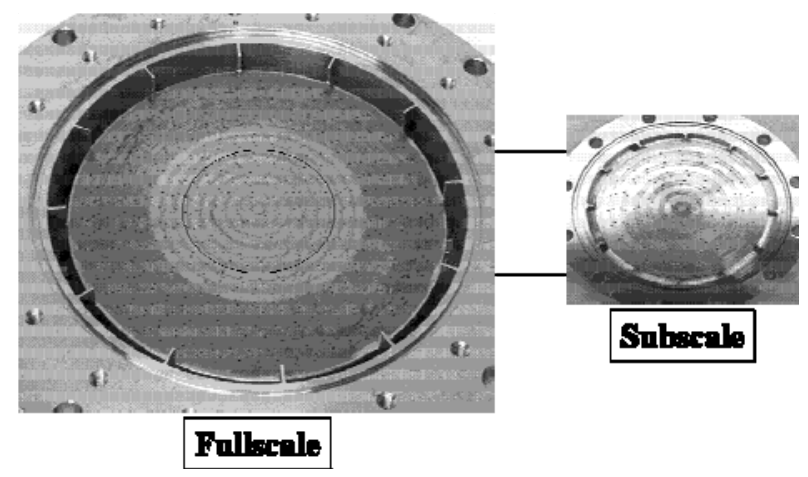

Figure 16. Comparison of OME fullscale and subscale injector hardware. ${ }^{36}$

Critical metering and injection features of the injector were fabricated by platelet technology, a manufacturing process that bonds thin metal sheets etched with desired features into a monolithic structure. ${ }^{34}$ The element used for 
the final design was a transverse like-on-like doublet, a modification by the use of platelet technology of the typical like-on-like doublet. ${ }^{33-37}$ Other elements investigated in development included unlike-doublets, splash plates, and other platelet-modified like-on-like doublets. ${ }^{35,36}$

Subscale hardware was used extensively in the development program. Subscale sizes included a $2.7 \mathrm{kN}$ (600 lbf) thrust in $6.9 \mathrm{~cm}$ (2.7”) chamber diameter combustor, and a $4.4 \mathrm{kN}$ (1000 lbf) thrust in $8.9 \mathrm{~cm}$ (3.5”) chamber diameter combustor. ${ }^{14,35,36}$ Both used L' of $12.7 \mathrm{~cm}$ (5”). A comparison of subscale and fullscale hardware for a development unlike-doublet element is shown in Fig. $16 .^{36}$ While the use of this subscale hardware was informative for the combustion stability verification, ${ }^{14,37}$ we will review the performance comparisons.

$2.7 \mathrm{kN}$ thrust injector Isp-based performance for a variety of elements is shown in Fig. $17 .^{33}$ Included in this figure are data from the single element testing, using an L' of $10.2 \mathrm{~cm}$ (4”). ${ }^{33}$ As discussed previously, the difference between single element and multi-element performance can be an indication of the interelement interaction, $X_{i a}$. However, in two cases as illustrated in Fig. 17, the single element performance is higher than the multi-element performance, indicating that $X_{i a}$ can be less than one. However, the mixing continues to improve with these elements because for all cases the performance increases with increasing L'.

Based on the delivered Isp of the flight engine, the ERE of the flight combustor was 98\%.33,34 There were no barrier-cooling schemes in the final configuration, ${ }^{35}$ so there were no intentional maldistributions. Performance in the subscale hardware was within $0.5 \%$ of this value, within the range of practical experimental error. ${ }^{35,36}$

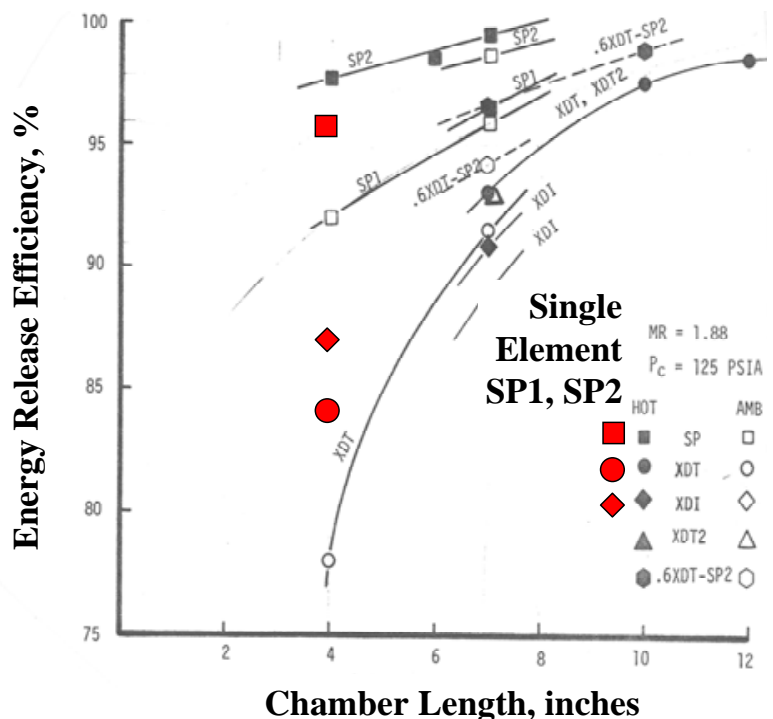

Figure 17. Comparison of OME multi-element and single element performance. ${ }^{33}$

\section{NASA LeRC Thrust/Element Tests}

While not a scaling study per se, where various elements are tested in combustion chambers of different dimensions, the work at the NASA Lewis Research Center (LeRC) in the 1960s is an informative study of scaling the element size. ${ }^{38}$ The combustor is shown in Fig. 18. Chamber diameter was $27.4 \mathrm{~cm}$ (10.78 in.). Propellants were liquid oxygen and cold gaseous hydrogen, with chamber pressure of $2.064 \mathrm{MN} / \mathrm{m}^{2}$ (300 psia). ${ }^{38}$ Injector elements of similar geometry but widely varying thrust (or flowrate)-per-element characteristics were tested in this chamber. Figure 19 shows injector faces for the smallest and largest elements tested.

Results of this study are shown in Figs. 20 and $21 .^{38}$ As expected, the performance efficiency increases with decreasing element size. At fixed L' of $30.5 \mathrm{~cm}$ (12"), the $89 \mathrm{~N}$ (20 lbf) elements obtained the highest performance. $222 \mathrm{~N}$ (50 lbf), $445 \mathrm{~N}$ (100 lbf), and $890 \mathrm{~N}$ (200 lbf) elements were grouped together at slightly lower performance. $2.5 \mathrm{kN}$ (572 lbf) and $4.4 \mathrm{kN}$ (1000 lbf) elements suffered a dramatic reduction in performance. 


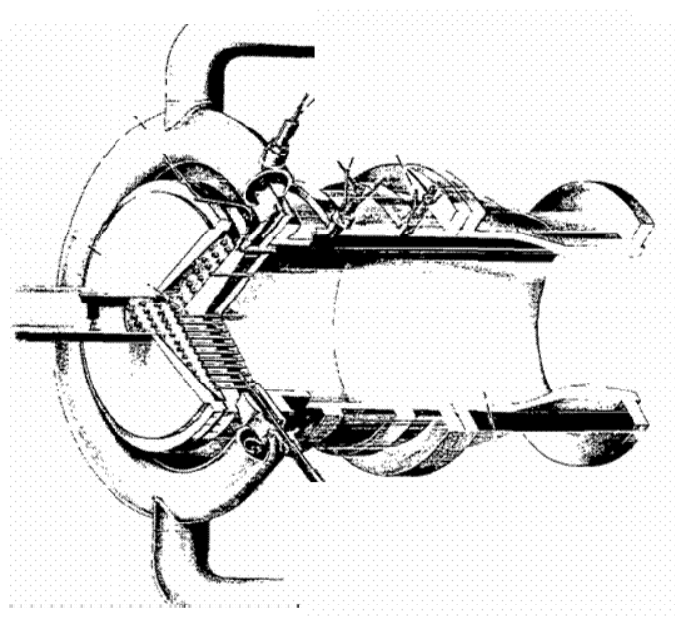

Figure 18. $89 \mathrm{kN}(20 \mathrm{Klbf})$ thrust chamber for NASA LeRC injector element comparisons. ${ }^{38}$

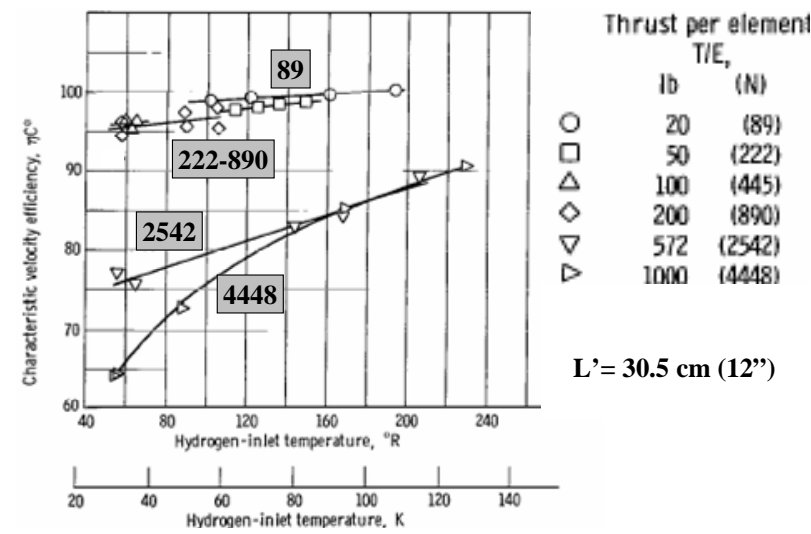

Figure 21. $\eta_{C^{*}}$ comparison of NASA LeRC testing with varying thrust/element. ${ }^{38}$
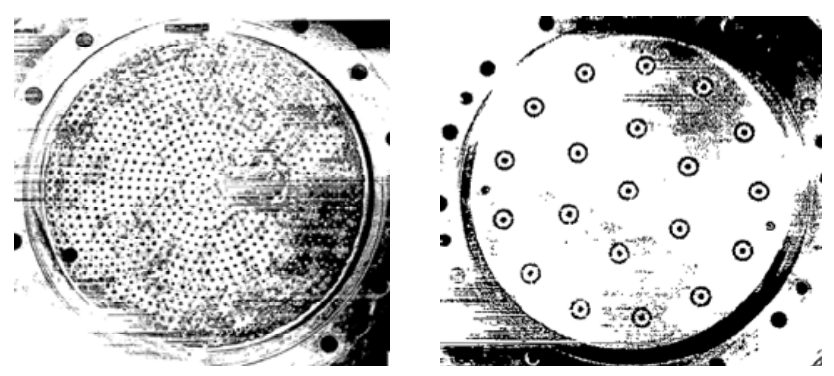

$89 \mathrm{~N}(20 \mathrm{lbf}) /$ Element
4.4 kN (1000 lbf)/Element
Figure 19. Injector element patterns for NASA LeRC element scaling testing. ${ }^{38}$

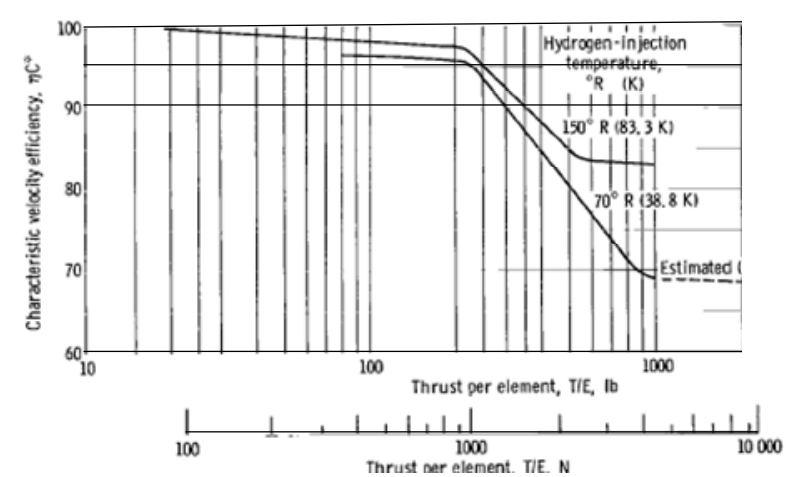

Figure 20. $\eta_{C^{*}}$ comparison of NASA LeRC testing with varying thrust/element. ${ }^{38}$

It is important to realize this performance loss of the coarse elements turns out to be vaporization-limited. If the coarse elements are tested in a longer combustion chamber, the performance is dramatically increased, as shown in Fig. 22. $\eta_{\mathrm{C}^{*}}$ of the $4.4 \mathrm{kN}$ element increased by more than 25 percentage points when the $\mathrm{L}^{\prime}$ was increased from $30.5 \mathrm{~cm}$ to $55.9 \mathrm{~cm}$. Also included on Fig. 22 are data from the subscale M-1 testing, which tested a similar coaxial injection element design with a similarly large thrust/element. This element achieved $\eta_{\mathrm{C}^{*}}$ as high as the $445 \mathrm{~N}$ element in a chamber with sufficient L'. These results demonstrate the critical scaling relationship between element and combustion chamber dimensions.

\section{Summary and Conclusions}

Developing full-scale liquid rocket thrust chambers, especially for booster engines, is still an expensive and time-consuming process because most of the development testing occurs with full-size hardware rather than something smaller. Full-scale hardware is used because no well-defined development methodology for using smaller size hardware is generally accepted throughout the rocket engine community. Unfortunately, a "holy grail" of scaling has never been invented which can provide in a single demonstration verification of all the important processes for a LPRE combustor - performance, heat transfer, compatibility, combustion stability, and ignition. 


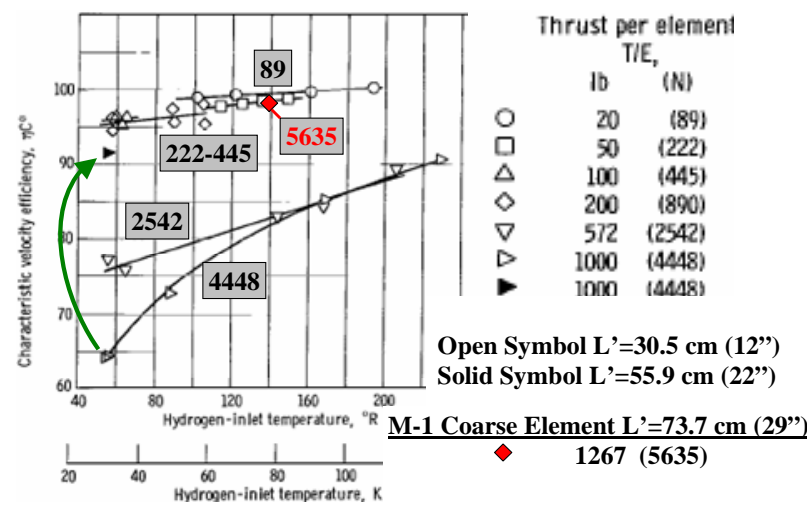

Figure 22. $\eta_{C^{*}}$ comparison of NASA LeRC and M-1 subscale testing with variations in $L^{,} \cdot{ }^{31,38}$

Certainly one reason for this lack of invention is that scaling of the combustion flow in a LPRE with full similarity of the internal aerothermochemistry is not practical, even for steady conditions. There are simply too many conflicting requirements. Even partial similarity was found to be difficult; Penner and Crocco developed two scaling rules, discussed herein, where some distortion of the injector or chamber geometry, and manipulation of the chemical conversion times, were required.

However, LPRE combustors have been developed with scaled hardware, even when violating similarity rules. One scaling relationship - the use of constant element dimensions in combustion chambers of different diameters and lengths - has been used in many programs and shown to succeed in validating the performance of the larger combustor, but only when features of the chamber geometries are properly modeled and all performance subelements are included. The use of this relationship for combustion stability scaling has limitations and must be applied with caution, however. Another scaling relationship based on the Hewitt Correlation - the use of photoscaled element dimensions in photo-scaled combustion chambers - has been shown to successfully predict combustion stability characteristics but is not yet generally proven for performance. Aspects of photo-scaled hardware remain to be evaluated.

The investigation of proper scaling rules for LPRE combustor development continues today. Validated scaling methods can provide value, even for current development, where higher performance is desired at lower cost, lower weight, and with shorter schedules.

Certainly one of the most significant differences between the current era and the past is analysis capability, represented by the increasing use of CFD methods, especially for combustion and droplet-laden flows. While the use of CFD as a design tool for rocket engine combustor development generally lags behind the rest of the combustion industry (in no small part due to the significant increase in mass flux and energy density of the problem, along with the predominant use of two-phase flows), the last 10 years have seen a dramatic increase in the use of CFD in this field. CFD, used in carefully crafted "numerical experiments," can advance the development of the scaling methodology as much as the investigation of the historical database, or the conduct of hardware-oriented experiments. These avenues are currently being explored at the NASA MSFC, and future publications showing the results of such "numerical experiments" in relation to aspects of scaling are planned.

\section{Acknowledgments}

Portions of this paper were originally presented at the $25^{\text {th }}$ Anniversary Meeting of the Northern branch of the Japan Society of Aerospace Sciences at Sendai, Japan, on March 3, 2007. The opportunity to make that presentation is acknowledged. 


\title{
References
}

\author{
${ }^{1}$ Penner, S.S., Chemical Problems in Jet Propulsion, Pergamon Press, London, 1957, pp. 345-347, 376-388. \\ 226. \\ ${ }^{2}$ Harrje, D.T., and Reardon, F.H., (eds.), Liquid Propellant Rocket Combustion Instability, NASA SP-194, 1972, pp. 221- \\ ${ }^{3}$ Weller, A.E., "Similarities in Combustion, A Review," Selected Combustion Problems, II, AGARD Combustion \\ Colloquium, 1956, pp. 371-383. \\ ${ }^{4}$ Stewart, D.G., "Scaling of Gas Turbine Combustion Systems," Selected Combustion Problems, II, AGARD Combustion \\ Colloquium, 1956, pp. 384-413. \\ ${ }^{5}$ Penner, S.S., "Similarity Analysis for Chemical Reactors and the Scaling of Liquid Fuel Rocket Engines," Combustion \\ Research and Reviews, AGARD, 1955, pp. 140-162. \\ ${ }^{6}$ Crocco, L., "Considerations on the Problem of Scaling Rocket Engines" Selected Combustion Problems, II, AGARD \\ Combustion Colloquium, 1956, pp. 457-468. \\ ${ }^{7}$ Penner, S.S., and Datner, P.P., "Combustion Problems in Liquid-Fuel Rocket Engines," Proceeding of the Fifth Symposium \\ on Combustion, Sept. 1954, pp. 11-28. \\ ${ }^{8}$ Penner, S.S., and Fuhs, A.E., "On Generalized Scaling Procedures for Liquid-Fuel Rocket Engines," Combustion and \\ Flame, Vol. 1, 1957, pp. 229-240. \\ ${ }^{9}$ Penner, S.S., "On the Development of Rational Scaling Procedures for Liquid-Fuel Rocket Engines," Jet Propulsion, Sept. \\ 1957, pp. 156-161. \\ ${ }^{10}$ Ross, C.C., "Scaling of Liquid Fuel Rocket Combustion Chambers" Selected Combustion Problems, II, AGARD \\ Combustion Colloquium, 1956, pp. 444-456. \\ ${ }^{11}$ Spaulding, D.B., “The Art of Partial Modeling," $9^{\text {th }}$ International Symposium on Combustion, The Combustion Institute, \\ 1963, pp. 833-843. \\ ${ }^{12}$ Lawhead, R.B., and Combs, L.P., “Modeling Techniques for Liquid Propellant Rocket Combustion Processes,” $9^{\text {th }}$ \\ International Symposium on Combustion, The Combustion Institute, 1963, pp. 973-981. \\ ${ }^{13}$ Beer, J.M., and Chigier, N.M., Combustion Aerodynamics, Chapter 7, “Modeling of Combustion Systems,” pub. John \\ Wiley \& Sons, New York, 1972, pp. 196-211. \\ ${ }^{14}$ Dexter, C.E., Fisher, M.F., Hulka, J.R., Denisov, K.P., Shibanov, A.A., and Agarkov, A.F., "Scaling Techniques for \\ Design, Development and Test," Liquid Rocket Thrust Chambers: Aspects of Modeling, Analysis, and Design, edited by V. Yang, \\ M. Habiballah, J. Hulka, and M. Popp, Progress in Astronautics and Aeronautics, Vol. 200, AIAA, Washington, DC, 2004, pp. \\ 553-600. \\ ${ }^{15}$ Anderson, W.E., Sisco, J.C, Long, M.R., and Sung, I.-K., “Scaling Test Methods for Combustion Devices,” Fifth \\ International Symposium on Liquid Space Propulsion (CD-ROM), Chattanooga, TN, USA, 28-30 October, 2003. \\ ${ }^{16}$ Fisher, S.C., Dodd. F.E., and Jensen, R.J., “Scaling Techniques for Liquid Rocket Combustion Stability Testing,” Liquid \\ Rocket Engine Combustion Instability, edited by V. Yang, and W. Anderson, Progress in Astronautics and Aeronautics, Vol. 169, \\ AIAA, Washington, DC, 1995, pp. 545-564. \\ ${ }^{17}$ Delabroy, O., Lacas, F., Labegorre, B., and Samaneigo, J.-M., "Paramètres de Similitude Pour la Combustion Diphasique," \\ Rev. Gén. Therm, 37, 1998, pp. 934-953. (in French). \\ 18“"JANNAF Rocket Engine Performance Prediction and Evaluation Manual,” CPIA Publication 246, April 1975. \\ ${ }^{19}$ Coats, D.E., “Assessment of Thrust Chamber Performance,” Liquid Rocket Thrust Chambers: Aspects of Modeling, \\ Analysis, and Design, edited by V. Yang, M. Habiballah, J. Hulka, and M. Popp, Progress in Astronautics and Aeronautics, Vol. \\ 200, AIAA, Washington, DC, 2004, pp. 601-620. \\ ${ }^{20}$ Huzel, D.K., and Huang, D.H., “Modern Engineering for Design of Liquid-Propellant Rocket Engines,” Progress in \\ Astronautics and Aeronautics, Vol. 147, AIAA, Washington, DC, 1992. \\ ${ }^{21}$ Anderson, W.E., Ryan III, H.M., Santoro, R.J., and Hewitt, R.A., “Combustion Instability Mechanisms in Liquid Rocket \\ Engines Using Impinging Jet Injectors,” AIAA Paper No. 95-2357, July 1995. \\ ${ }^{22}$ Hewitt, R.A., "Combustion Instability in Liquid Rockets (with a d/V Correlation Perspective),” invited lecture delivered at \\ the $31^{\text {st }}$ AIAA/ASME/SAE/ASEE Joint Propulsion Conference, July 10, 2006. \\ ${ }^{23}$ Hewitt, R.A., personal communication. \\ ${ }^{24}$ Priem, R.J., and Heidmann, M.F., "Propellant Vaporization as a Design Criterion for Rocket-Engine Combustion \\ Chambers," NASA TR-67, 1960. \\ ${ }^{25}$ Lefebvre, A.H, Atomization and Sprays, Hemisphere Publishing Co., 1989, pp 202-222. \\ ${ }^{26}$ Kenny, R.J., Moser, M.D., Hulka, J., and Jones, G., "Cold Flow Testing For Liquid Propellant Rocket Injector Scaling and \\ Throttling,” AIAA Paper No. 2006-4705, July 2006. \\ ${ }^{27}$ Mueller, J., “Thruster Options for Microspacecraft: A Review and Evaluation of Existing Hardware and Emerging \\ Technologies,” AIAA Paper No. 97-3058, July 1997. \\ ${ }^{28}$ Bruno, C., "Chemical Microthrusters: Effects of Scaling on Combustion,” AIAA Paper No. 2001-3711, July 2001.
}


${ }^{29}$ Barsotti, R.J., Datsko, S.C., Louison, R., Kovach, R.J., Miller, D.J., and Pullman, W.P., "Development of Liquid Oxygen/Liquid Hydrogen Thrust Chamber for the M-1 Engine, Technology Report,” Aerojet General Corp., NASA CR 54813, AGC 9400-5, May 15, 1968.

${ }^{30}$ Dankhoff, W.F., Johnson, I.A., Conrad, E.W., and Tomazic, W.A., "M-1 Injector Development - Philosophy and Implementation,” NASA Lewis Research Center, TN D-4730, Aug. 1968.

${ }^{31}$ Scott, H.E., Bloomer, H.E., and Mansour, A.H., “M-1 Engine Subscale Injector Tests,” NASA Lewis Research Center, TN D-4053, July 1967.

${ }^{32}$ Muss, J.A., Nguyen, T.V., and Johnson, C.W., "User’s Manual for Rocket Combustor Interactive Design (ROCCID) and Analysis Computer Program, Volume I,” NASA CR-187109, May 1991.

${ }^{33}$ Neill, T., "Flight and Development History of the Highly Reliable Space Shuttle Orbital Maneuvering Engine," AIAA Presentation, 42 ${ }^{\text {nd }}$ AIAA/ASME/SAE/ASEE Joint Propulsion Conference, Sacramento, CA, July 12, 2006.

${ }^{34}$ David, D., "Space Shuttle Orbit Maneuvering Subsystem (OMS) Rocket Engine Development Status Update - July 1977,” AIAA Paper No. 77-811, July 1977.

${ }^{35}$ Kahl, R.C., LaBotz, R.J., and Bassham, L.B., "Platelet Injectors for Space Shuttle Orbit Maneuvering Engine,” AIAA Paper No. 74-1108, October 1974.

36،"Space Shuttle Orbit Maneuvering Engine Platelet Injector Program,” NASA CR-151442, Aerojet Liquid Rocket No. Final Report 13133-F-1, Dec. 1975.

${ }^{37}$ Hurlbert, E.A., Sun, J.L., and Zhang, B., “Instability Phenomena in Earth Storable Bipropellant Engines,” Liquid Rocket Engine Combustion Instability, edited by V. Yang, and W. Anderson, Progress in Astronautics and Aeronautics, Vol. 169, AIAA, Washington, DC, 1995, pp. 113-142.

${ }^{38}$ Salmi, R.J., Wanhainen, J.P., and Hannum, N.P., "Effect of Thrust Per Element on Combustion Stability Characteristics of Hydrogen-Oxygen Rocket Engines,” NASA Lewis Research Center, TN D-4851, Oct. 1968. 